\title{
Pensamento histórico de jovens estudantes sobre o Brasil: uma análise a partir das contribuições da Educação Histórica ${ }^{1}$
}

\section{Historical thinking of young students about Brazil: an analysis from the contributions of Historical Education}

\author{
Aaron Sena Cerqueira Reis*
}

\begin{abstract}
RESUMO
Neste artigo, objetiva-se compreender o pensamento histórico de jovens estudantes sobre o Brasil. A partir das contribuições teórico-metodológicas da Educação Histórica, analisamos os conceitos substantivos e de segunda ordem mobilizados para responder a seguinte questão: Considerando as noticias que você obteve por meio de telejornais, revistas, internet ou outros meios de comunicação, como você explicaria a atual situação do Brasil? As respostas dos 111 participantes foram analisadas segundo os pressupostos da Grounded Theory. Com este método, identificamos diferentes conceitos que foram categorizados em um dendograma composto por três classes. Este processo foi auxiliado pelo IRAMUTEQ, software que viabiliza diferentes tipos de análise textual com base na frequência das palavras. Os resultados implicaram na compreensão de agentes, entidades, dentre outros fatores relacionados à ideia de "crise" (classe 3). Além disso, os estudantes lançaram mão de explicações, baseadas em "causas" (classe 1) e "consequências" (classe 2) para o referido conceito substantivo.

Palavras-chave: Educação Histórica. Ensino de História. Pensamento Histórico. Estudantes.
\end{abstract}

1 Trabalho realizado com apoio da Coordenação de Aperfeiçoamento de Pessoal de Nível Superior (CAPES).

*Universidade Tiradentes. Aracaju, Sergipe, Brasil. E-mail: aaron_sena@hotmail.com https://orcid.org/0000-0001-8970-4941 


\begin{abstract}
This paper aims to understand the historical thinking of young students about Brazil. From the theoretical-methodological contributions of Historical Education, we analyze the substantive and second-order concepts mobilized to answer the following question: Considering the news that you obtained through news programs, magazines, the internet or other means of communication, how would you explain current situation in Brazil? The responses of the 111 participants were analyzed according to Grounded Theory assumptions. With this method, we identified different concepts that were categorized into a dendrogram composed of three classes. This process was aided by IRAMUTEQ, software that enables different types of textual analysis based on the frequency of words. The results implied the understanding of agents, entities, among other factors related to the idea of "crisis" (class 3). In addition, students used explanations, based on "causes" (class 1) and "consequences" (class 2) for the said substantive concept.
\end{abstract}

Keywords: Historical Education. History Teaching. Historical Thinking. Students.

\title{
Introdução
}

Nos últimos anos, uma série de acontecimentos repercutiu no cenário político brasileiro fomentando a necessidade de uma reflexão crítica acerca do nosso contexto psicossocial. Fatos como o "impeachment" da presidenta Dilma Rousseff e a ascensão de Michel Temer, por exemplo, foram eventos que, de certo modo, causaram impacto na vida prática da população, repercutindo, inclusive, nos processos de construção do nosso pensamento histórico - fenômeno que pode ser entendido como um conjunto de operações cognitivas que habilitam o indivíduo a ler o mundo historicamente.

Seguindo o conjunto de investigações de esquemas de corrupção promovido pela Polícia Federal brasileira - mais conhecido como Operação lava-jato -, estes acontecimentos contribuíram não apenas com a polarização política que ainda hoje repercute no país, como também suscitam a emergência (assustadora) de ideias revisionistas. Com o fito de garantir expressivo número de apoiadores, representantes de uma esfera política conservadora - em sua grande maioria tentam controlar a informação e deturpar o conhecimento científico, afetando a Educação Brasileira e, consequentemente, o ensino de História. 
Neste estudo, buscamos entender o pensamento histórico de estudantes do Ensino Fundamental sobre o Brasil. A partir das contribuições teóricometodológicas da Educação Histórica, analisamos os conceitos substantivos e de segunda ordem mobilizados para caracterizar, ou mesmo perspectivar o país durante o tempo vivido pelos/as próprios/as participantes. Em outras palavras, esperamos perceber o modo como os jovens se localizam no tempo, entendendo que o passado pode abrir possibilidades de projeção para o futuro - procedimento capaz de evidenciar a consciência histórica do grupo.

Segundo Lee (2005), os conceitos substantivos estão relacionados aos mais diferentes aspectos da atividade humana (econômico, político, social e cultural), ainda que a apreensão destas ideias possa gerar dificuldades devido a mudança de seus significados no tempo e no espaço. Articulados aos mesmos, podemos localizar os conceitos meta-históricos, disciplinares ou de segunda ordem, conceitos que, embora não componham o objeto de estudo do historiador, subjazem as construções da disciplina e narrativa históricas. Estes mecanismos de raciocínio são utilizados para a construção do pensamento histórico e, por isto, são importantes para o aprendizado disciplinar, além dos processos de atribuição de sentidos aos conteúdos históricos.

Para Kitson, Husbands e Steward (2015), os conceitos de segunda ordem compõem a natureza investigativa do ensino de História. Assim, como um processo investigativo, a história contribui para que estudantes desempenhem um papel ativo na construção de seu próprio conhecimento. Um exemplo concreto apresentado por estes pesquisadores é o conceito de "evidência" (KITSON; HUSBANDS; STEWARD, 2015). Entendida como um conjunto de inferências que podemos extrair de fontes históricas, a evidência deve ser utilizada para construção de explicações acerca de um problema sobre o passado.

Corroborando esta ideia, Wineburg (2007) afirma que a evidência faz da história uma disciplina "não natural", isto é, diferente de outras formas de conhecimento utilizadas para estabelecer conexão com o passado. Por meio dela, desenvolve-se o pensamento histórico, cujo processo se diferencia do pensamento comum por não se basear, apenas, em um aprendizado que associa novas informações às informações já conhecidas. Assim, este pesquisador entende que o pensamento histórico exige do sujeito a habilidade de contextualização das fontes, de maneira que, sobre elas, não sejam lançadas apenas críticas, mas sobretudo, questões capazes de favorecer a compreensão de lacunas de um dado momento histórico (WINEBURG, 2007).

Os conceitos de segunda ordem são importantes por introduzirem desafios que vão além do reconhecimento de fatos e, também, por oferecerem ideias de como a "história dos historiadores" opera. Além do conceito de evidência, é possível entender o passado a partir de outras concepções. Kitson, Husbands 
e Steward (2015) citam, por exemplo, os conceitos de: compreensão empática ou empatia, que se constitui como uma predisposição, um esforço realizado para entender os agentes do passado no contexto de suas crenças, atitudes e comportamentos; explicação histórica, conceito que incide sobre as formas de pensar as causas e consequências para estruturação da escrita; e também, a interpretação, que, ao favorecer a compreensão da natureza da história como um processo investigativo, revela a inexistência de relatos fixos.

O desenvolvimento do pensamento histórico por meio de conceitos de segunda ordem é essencial para o aprendizado histórico. Desta forma, a história escolar passa a ser refletida em termos de uma literacia histórica (historical literacy), em que o indivíduo em situação de aprendizagem se torna capaz, não apenas de memorizar conhecimentos factuais, mas sobretudo, de desenvolver uma compreensão conceitual e procedimental, tornando possível contextualizar e aplicar os conhecimentos advindos do passado (LEE, 2011; CHAPMAN, 2015). Concebido como literacia (ou alfabetização), o aprendizado histórico ocorre a partir do desenvolvimento de um pensamento disciplinar, cujos desafios não devem se restringir a lemas polarizadores a exemplo de "tradicional versus progressista", "centrado na criança versus centrado na matéria" ou "habilidades versus conteúdos" (LEE, 2016).

Considerando que "há mais na história do que somente acúmulo de informações sobre o passado", Lee (2006, p. 136) aponta a necessidade de uma noção "operacionalizável" de literacia histórica que pode ser construída a partir da matriz disciplinar de Rüsen (2001, 2015). Ao conectar história e vida prática, este instrumento do pensamento filosófico mostra como nossos interesses dirigem nossa compreensão histórica, permitindo-nos uma orientação no tempo. Portanto, na medida em que a história fornece um "senso da nossa própria identidade", viabilizando um "compromisso de indagação", o estudante passa a entender o conhecimento histórico a partir de ideias (de segunda ordem) que o torna possível (LEE, 2006, p. 135-6).

Como vertente da consciência histórica, a literacia histórica proposta por Lee contribui com o reconhecimento do caráter contraintuitivo presente nas ideias prévias de estudantes e que podem inviabilizar a história a partir de afirmações como: "o passado aconteceu e se foi" ou, então, "não estávamos lá para saber" (LEE, 2006; 2016). Tal reconhecimento, favorece a construção de modelos de progressão capazes de conduzir os estudantes a níveis mais elaborados da compreensão histórica que permite a "história prosseguir, ao invés de forçá-la a uma parada, fazendo mudanças na visão cotidiana da natureza e do estado do conhecimento do passado para um passado histórico" (LEE, 2016, p. 120).

É preciso ressaltar que a literacia histórica não fornece elementos capazes de definir se um indivíduo "sabe algo" de história. Entretanto, ela sugere algumas 
condições necessárias que contribuem para entendermos o que significa conhecer elementos desta disciplina, como: a compreensão de que a história é uma forma de ver o mundo; a aquisição de disposições que evitem “"saquearmos' o passado para produzir histórias convenientes para presentes fins"; e o desenvolvimento de uma imagem do passado que permita a orientação no tempo dos estudantes (LEE, 2011; 2016).

Ao debruçarmo-nos sobre o pensamento histórico de jovens estudantes, esperamos que este trabalho possa ser inserido em um conjunto de produções que valorizam os processos de ensino-aprendizagem da História, em que as construções mentais de professores/as e estudantes são tomadas como objeto, a exemplo de estudos como os de Barca (2000, 2006); Schmidt (2008, 2016); Schmidt e Garcia (2005); Cainelli (2019). Acreditamos que, ao conhecer as disposições internas do jovem, o/a professor/a tende a mediar o conhecimento produzido em sala de aula e, deste modo, talvez possa contribuir com a formação de um pensamento histórico mais crítico.

\section{Método}

Neste estudo, seguimos os pressupostos da investigação qualitativa, a qual preconiza a necessidade de observação do objeto em seu ambiente natural e cuja forma de apresentação é basicamente descritiva. Com esta perspectiva, nosso posicionamento recaiu sobre o processo e, por isso, nossas abstrações foram construídas ao longo da pesquisa. Assim, estivemos interessados nos modos como os sujeitos experimentaram, interpretaram e atribuíram sentidos ao fenômeno observado (BOGDAN; BIKLEN, 1994).

A pesquisa foi realizada em uma escola pública estadual, localizada no bairro Butantã, na cidade de São Paulo/SP, entre os meses de maio e junho de 2016. Participaram 111 estudantes, entre 12 e 16 anos de idade, dos gêneros masculino e feminino, distribuídos em turmas do $8^{\circ}$ e $9^{\circ}$ anos do Ensino Fundamental. Com a autorização de coordenadores e professores, realizamos um período de observação participante e, em seguida, aplicamos um instrumento para coleta de dados.

Convém ressaltar que, na ocasião, vivenciávamos o golpe que depôs a presidenta Dilma Rousseff. Engendrado por parlamentares - alguns deles julgados e, posteriormente, condenados por envolvimento em esquemas de corrupção, o fenômeno do "impeachment" gerou divergências, algumas das quais evidenciadas nas falas dos nossos participantes. A pesquisa, portanto, foi 
realizada sob uma conjuntura política marcada por uma guinada conservadora que lançava ataques à democracia e à diversidade cultural, bem como flertava com o retorno de práticas autoritárias (SEFFNER, 2019).

Inspirado em diferentes estudos, situados no campo da Educação Histórica (BARCA, 2000; SIMÃO, 2013; ALVES, 2011; RIBEIRO, 2012), o instrumento de pesquisa contou com a seguinte questão: Considerando as noticias que você obteve por meio de telejornais, revistas, internet ou outros meios de comunicação, como você explicaria a atual situação do Brasil? Cite um exemplo e comente. Por meio dele, buscamos identificar os conceitos substantivos relacionados ao Brasil do tempo presente, bem como os conceitos de segunda ordem que o estruturam, sobretudo, as noções de explicação. Com base nos elementos sugeridos na pergunta, supomos que as respostas poderiam tangenciar ideias ligadas aos aspectos políticos e econômicos do país, evidenciando conceitos substantivos como democracia e cidadania.

Fundamentada pela Grounded Theory de Strauss e Corbin (2008), a análise dos dados buscou estabelecer ou identificar conceitos, delimitando suas propriedades e dimensões para a compreensão do fenômeno estudado. As respostas apresentadas ao instrumento de pesquisa foram coligidas em um único corpus - que denominamos Brasil atual - e submetidas ao IRAMUTEQ, software que viabiliza diferentes tipos de análise textual. Com auxílio deste programa computacional, realizamos uma Classificação Hierárquica Descendente (CHD), tipo de análise multivariada que viabiliza a construção de categorias baseadas na frequência das palavras, cuja representação gráfica é um dendograma (CAMARGO; JUSTO, 2013).

\section{Resultados}

Ao submeter o corpus textual ao IRAMUTEQ, o software fragmentou as respostas em 117 segmentos de texto (ST), dos quais $96(82,05 \%)$ foram considerados na análise. Cada segmento de texto apresentou uma ocorrência de 22,26 palavras, cuja frequência no corpus foi de 4,04. Para a construção do dendograma abaixo, consideramos as palavras com frequência (f) igual ou superior a 3 e qui-quadrado $\left(\mathrm{x}^{2}\right)$ igual ou superior a 3,97 - este último coeficiente denota o poder de associação de uma palavra à classe. 
FIGURA 1 - CHD DO CORPUS BRASIL ATUAL

\begin{tabular}{|c|c|c|c|c|c|c|c|c|}
\hline \multirow{3}{*}{\multicolumn{3}{|c|}{$\begin{array}{c}\text { Classe } 2 \\
\text { Consequências } \\
28 \text { st }(29,17 \%)\end{array}$}} & \multirow{3}{*}{\multicolumn{3}{|c|}{$\begin{array}{c}\text { Classe } 1 \\
\text { Causas } \\
26 \text { st }(27,08 \%)\end{array}$}} & \multirow{3}{*}{\multicolumn{3}{|c|}{$\begin{array}{c}\text { Classe } 3 \\
\text { Crise } \\
42 \text { st }(43,75 \%)\end{array}$}} \\
\hline & & & & & & & & \\
\hline & & & & & & & & \\
\hline Palavras & f & $\mathbf{x}^{2}$ & Palavras & f & $\mathrm{x}^{2}$ & Palavras & f & $\mathrm{x}^{2}$ \\
\hline bom & 9 & 16.67 & causa & 17 & 36.40 & crise & 30 & 19.70 \\
\hline acontecer & 6 & 15.54 & corrupto & 5 & 14.20 & preço & 11 & 12.80 \\
\hline pior & 6 & 15.54 & Dilma & 10 & 14.11 & desemprego & 11 & 10.20 \\
\hline achar & 9 & 13.94 & Saber & 5 & 10.25 & caro & 6 & 8.23 \\
\hline ruim & 12 & 13.25 & merda & 3 & 8.34 & alimento & 6 & 8.23 \\
\hline ano & 5 & 12.81 & Brasil & 21 & 5.08 & alto & 6 & 8.23 \\
\hline dinheiro & 7 & 7.14 & & & & aumentar & 8 & 5.96 \\
\hline exemplo & 6 & 5.14 & & & & emprego & 6 & 5.40 \\
\hline só & 5 & 4.69 & & & & vez & 4 & 5.37 \\
\hline melhorar & 4 & 4.36 & & & & passar & 4 & 5.37 \\
\hline economizar & 3 & 4.24 & & & & gente & 3 & 3.98 \\
\hline & & & & & & valor & 3 & 3.98 \\
\hline & & & & & & aumento & 3 & 3.98 \\
\hline & & & & & & econômico & 9 & 3.97 \\
\hline
\end{tabular}

FONTE: Dendograma produzido com auxílio do IRAMUTEQ.

Conforme o dendograma, observamos que o corpus Brasil atual sofreu duas partições. A primeira delas, isolou a classe 3, separando-a das demais. Já a segunda, originou as classes 1 e 2. Quanto ao número de segmentos de texto (ST) retido, podemos observar uma distribuição ligeiramente equilibrada. No entanto, a mais representativa delas é a classe 3, constituída por $43,75 \%$ dos ST considerados na análise, seguida pelas classes 2 , com $29,17 \%$ dos ST e, da classe 1 , com $27,08 \%$.

\section{A ideia de "crise"}

Além de reter o maior número de segmentos de texto, a classe 3 evidencia a palavra mais frequente de todas as respostas consideradas na análise e que, na perspectiva dos jovens participantes, caracteriza a situação atual do Brasil: 
"crise" ( $\mathrm{f}=30)$. Embora não consigam elaborar definições complexas acerca deste conceito, por vezes, a ideia de crise é associada a expressões que se tornaram comuns em vários tipos de mídia e, possivelmente, mencionados em sala de aula, como "lava-jato", "lavagem de dinheiro" e "corrupção". Um outro termo bastante utilizado é o adjetivo "econômico" ( $\mathrm{f}=9)$ :

Uma crise que está afetando o país inteiro (estudante 125, gênero masculino, 14 anos, $8^{\circ}$ ano).

A atual situação do Brasil é a crise, nós estamos enfrentando uma crise absurda na economia (estudante 28 , gênero feminino, 14 anos, $9^{\circ}$ ano).

Que o Brasil está passando por uma crise e tá tendo muita corrupção, tipo lava-jato (estudante 80 , gênero masculino, 13 anos, $9^{\circ}$ ano).

A atual situação do Brasil é de recessão de forma política, financeira, cultural, temos como exemplo vários políticos envolvidos em corrupção exercendo normalmente seus cargos uma crise financeira, atitudes da sociedade que contrariam a honestidade (estudante 21, gênero feminino, 14 anos, $9^{\circ}$ ano).

A atual situação do Brasil crise econômica e corrupção de lavagem de dinheiro (estudante 43 , gênero masculino, 13 anos, $9^{\circ}$ ano).

Crise econômica afeta tudo e a todos porque tem gente que precisa de dois ou mais emprego para sustentar a família (estudante 71, gênero masculino, 14 anos, $9^{\circ}$ ano).

Observando as narrativas, é possível aproximarmos as ideias dos participantes a algumas das acepções apresentadas pelo Dicionário Houaiss da Língua Portuguesa, como: "estado de incerteza, vacilação ou declínio"; "episódio desgastante, complicado"; "situação de tensão, disputa, conflito"; "situação de falta, escassez, carência" (HOUAISS, 2009, versão eletrônica 3.0). Essas respostas expressam problemas do cotidiano que afetam, de alguma forma, a vida dos/as jovens, como o valor dos transportes públicos e dos alimentos, a desvalorização da moeda nacional em face à moeda estrangeira e o índice de violência, segundo observações dos próprios estudantes. Tais problemas são indicados a partir de palavras como "aumentar" $(\mathrm{f}=8)$, "alto" $(\mathrm{f}=6)$ e "aumento" $(\mathrm{f}=3)$ : 
O Brasil está em crise, muito desemprego, passagem de ônibus aumentando cada vez mais, os preços dos alimentos estão cada vez mais caros (estudante 60, gênero feminino, 13 anos, $9^{\circ}$ ano).

Eu acho que, com a crise econômica, os preços dos alimentos estão aumentando, prejudicando muito o povo brasileiro (estudante 79, gênero feminino, 14 anos, $9^{\circ}$ ano).

Estamos mudando de presidentes, o valor do dólar aumentou, estamos em crise de água, está havendo jogos do Brasil (estudante 47, gênero masculino, 14 anos, $9^{\circ}$ ano).

Eu acho que é uma situação prejudicial a muitas pessoas, por exemplo, os preços altos, as escolas em mal estado, a criminalidade aumentando e várias outras coisas que mostram a situação do nosso país (estudante 242 , gênero feminino, 13 anos, $8^{\circ}$ ano).

Percebemos, então, que uma significativa parte dos informantes tende a associar a ideia de crise a alguns aspectos da economia, como o aumento de "preços" dos mais diferentes bens de consumo. Entretanto, outra parte compara esta situação ao índice de "emprego" ou "desemprego". Nesse caso, as narrativas parecem tomar um discurso mais pessoal, quando mencionam casos próximos a sua própria realidade:

O Brasil está passando por uma situação financeira, muitas pessoas desempregadas, arroz e feijão aumentando, mais pra frente não vamos poder nem comprar o que comer. Então pra isso precisamos de um país mais digno (estudante 81, gênero feminino, 14 anos, $9^{\circ}$ ano).

Em crise, meu pai foi desligado recentemente de seu emprego, os produtos mais caros, entre outros (estudante 115, gênero masculino, 12 anos, $8^{\circ}$ ano).

Está sendo muito difícil para arrumar emprego por causa da crise, também podia baixar mais coisas de alimento... O Brasil podia melhorar sem essas corrupções (estudante 68, gênero masculino, 14 anos, $9^{\circ}$ ano).

A crise econômica porque o preço alto das comidas as economias financeiras que muitas pessoas estão ficando sem empregos. Algumas fazem uns bicos aqui e ali (estudante 24, gênero masculino, 14 anos, $9^{\circ}$ ano). 


\section{Explicações baseadas na ideia de "causa"}

Enquanto a maior parte dos estudantes se esforçou para definir, ou pelo menos, apresentar aspectos da situação atual do Brasil, conforme observamos na classe anterior, um pequeno grupo buscou identificar as possíveis "causas" ( $\mathrm{f}=17$ ) que contribuíram para a atual "crise". É o que observamos nas narrativas reunidas na classe 1 :

A situação do Brasil tá precária por causa da roubalheira na política e fora da política alguns partidos levaram o Brasil a um termo muito ruim (estudante 126, gênero masculino, 13 anos, $8^{\circ}$ ano).

Por causa da crise está todo mundo sem grana (estudante 46, gênero masculino, 13 anos, $9^{\circ}$ ano).

Bom, o Brasil não é tudo de bom, né? Mas todo mundo gosta. Bom, a tá acabando por causa de pessoas que não sabe economizar (estudante 14, gênero feminino, 15 anos, $9^{\circ}$ ano).

Eu acho que a situação do Brasil está muito ruim por causa da crise na minha opinião o que está mais grave é a economia dos brasileiros (estudante 88, gênero masculino, 14 anos, $9^{\circ}$ ano).

A primeira ideia que podemos extrair das respostas apresentadas é a de que a situação ocorre em virtude de conjunturas e agentes internos, evidenciados no uso frequente do substantivo próprio "Brasil" ( $\mathrm{f}=21)$. Dessa forma, não há menção a agentes ou países estrangeiros, por exemplo, mas sim ao próprio povo, aos políticos e instituições brasileiras. Todavia, é interessante notar que, em nenhum momento, os estudantes se culpabilizam, ou ao menos se inserem na concepção de "povo brasileiro", o que, talvez possa ser explicado pela dificuldade em se perceber como agente histórico, ou ainda, à dificuldade de compreender a situação que descrevem. Considerando que as causas são encontradas no próprio país, as principais hipóteses estão centradas em palavras como "corrupto" $(\mathrm{f}=5)$ e "Dilma" $(\mathrm{f}=10)$ : 
O Brasil está em uma situação não muito agradável por causa dos nossos governantes corruptos que só pensam em dinheiro (estudante 44, gênero masculino, 13 anos, $9^{\circ}$ ano).

Hoje o Brasil está em crise por causa de políticos corruptos e da Dilma (estudante 90 , gênero feminino, 13 anos, $9^{\circ}$ ano).

Particularmente tá uma bosta. O Brasil tá em uma crise que só Deus na causa. Esses partidos não estão colaborando com o povo brasileiro igual o partido da Dilma (estudante 13, gênero feminino, 14 anos, $9^{\circ}$ ano).

Pelo que eu sei o Brasil está em um momento difícil por causa da Dilma que fez promessas falsas (estudante 54, gênero masculino, 14 anos, $9^{\circ}$ ano).

Segundo os participantes, os elementos causadores da crise advêm tanto de esferas mais abrangentes da sociedade, a exemplo da corrupção ligada à política, ao governo ou aos políticos, como a agentes mais específicos, no caso da ex-presidenta Dilma Rousseff. Podemos observar assim, uma interessante capacidade de conjecturar hipóteses, mesmo quando afirmam não compreender bem a situação. Além disso, denotam interesse em solucionar os problemas elencados, apesar de não saberem como o fazer. Por fim, arriscam-se a projetar algumas expectativas:

Bom, eu não sei muito bem a situação do Brasil, mas creio que tenha melhorado, vi que o dólar caiu, mas vi também que com a saída da Presidente Dilma não mudou em quase nada (estudante 7, gênero feminino, 15 anos, $9^{\circ}$ ano).

A política a política está extremamente corrupta não há dúvidas sobre isso que na minha opinião está acabando com o Brasil. Mas o que fazer? Não sabemos escolher nada sobre o assunto (estudante 69, gênero feminino, 15 anos, $9^{\circ}$ ano).

Me desculpe o palavreado, mas está uma merda com esse impeachment da Dilma e olha daqui a pouco tem o do Michel Temer porque o povo não se contenta com o que tem (estudante 118, gênero feminino, 12 anos, $8^{\circ}$ ano). 


\section{Explicações baseadas na ideia de "consequência"}

Finalmente, analisamos a classe 2 que representa, sobretudo, algumas das consequências advindas da referida "crise". Embora as narrativas aqui agrupadas não mencionem diretamente uma relação de causa-consequência, os adjetivos utilizados pelos participantes, mesmo quando antagônicos, evidenciam os efeitos da situação que descrevem sobre o Brasil. Vejamos o emprego de palavras como "bom" ( $\mathrm{f}=9)$, "pior" ( $\mathrm{f}=6)$ e "ruim" $(\mathrm{f}=12)$ :

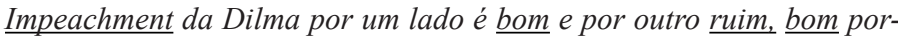
que pode entrar uma pessoa melhor, e ruim é que pode entrar um pior (estudante 244, gênero masculino, 13 anos, $8^{\circ}$ ano).

A situação do Brasil não está boa. Olha aí o PT dividindo o Brasil em duas partes, que eu acho que não é bom esse caso (estudante 248, gênero feminino, 13 anos, $8^{\circ}$ ano).

(...) Existem muitos pormenores bons e ruins sobre o país (...) Políticos mentem para ganhar a eleição e prometem inúmeras coisas e não fazem nada, apenas desviam dinheiro de obras públicas e isso causa a má qualidade das obras públicas (estudante 33, gênero masculino, 13 anos, $9^{\circ}$ ano).

O Brasil está quebrado, financeiramente quebrado, um presidente que acabou de assumir o cargo e a polícia descobre desvio de dinheiro todo dia e parece que vai ficar assim um bom tempo porque o país só vai de mal a pior (estudante 23, gênero masculino, 14 anos, $9^{\circ}$ ano).

A lava jato. Esse esquema de lavagem de dinheiro só vai fazer o Brasil ir de mal a pior, pois sem dinheiro, os preços dos impostos aumentame assim, muitos imigram pra outros países (estudante 127, gênero masculino, 12 anos, $8^{\circ}$ ano).

De acordo com as respostas apresentadas, nota-se que a crise no Brasil traz uma série de resultados incertos ou negativos de ordem política, econômica e social. Considerando o primeiro aspecto, eventos como o impeachment da presidenta Dilma ou as ações do Partido dos Trabalhadores (PT) são mencionados para demonstrar possíveis adversidades, embora as narrativas não denotem certeza 
sobre esse posicionamento. Por outro lado, destacam-se problemas relacionados à "roubalheira", "desvio de dinheiro" e "aumento de impostos", situações que resultam na má qualidade do serviço público e que pioram a economia do país. Finalmente, podemos depreender que, na concepção dos estudantes, essas questões podem contribuir, inclusive, para o processo de migração, uma questão social considerada importante, posto que mencionada, mas cujos impactos talvez não sejam bem compreendidos, já que foram omitidos. Apesar da menção a consequências relacionadas a eixos mais abrangentes, também observarmos questões específicas a partir dos seguintes "exemplos" ( $\mathrm{f}=6)$ :

A situação está muito ruim, um exemplo é a falta de água, a falta de água no Brasil está grave e as pessoas não estão ajudando a economizar (estudante 76, gênero masculino, 13 anos, $9^{\circ}$ ano).

A situação tá bem ruim não só por causa do governo, como pelo povo brasileiro. As coisas aqui no Brasil está muito cara e os lugar está muito ruim. Exemplo: Está tudo sujo e falta mais hospitais (estudante 9, gênero masculino, 14 anos, $9^{\circ}$ ano).

Eu acho que a situação do Brasil vai de mal a pior, não só pela presidência, mas pelo partido inteiro, exemplo a situação da Petrobrás que desviou bilhões de reais do nosso bolso (estudante 240, gênero masculino, 14 anos, $8^{\circ}$ ano).

Pontuadas as consequências, os estudantes chegam à conclusão de que é preciso haver mudanças. Observemos o uso de palavras como "melhorar" $(\mathrm{f}=4)$ e "economizar" $(\mathrm{f}=3)$ :

A situação promete melhorar, mas está muito ruim por conta de vários aspectos. Um deles era a ex-presidenta Dilma e a situação econômica, mas com a chegada de um novo(a) presidente tudo promete melhorar (estudante 93, gênero masculino, 14 anos, $9^{\circ}$ ano).

Eu acho que o Brasil só piorou com a entrada da Presidente Dilma e tem muito o que melhorar, muitos Brasileiros sem empregos, sem casas e também sem o que comer (estudante 16, gênero masculino, 13 anos, $9^{\circ}$ ano). 
O Brasil é um dos países (culpa da Dilma) mais ricos em tudo, mas a atual situação do Brasil é muitas mortes e desemprego, falta de hospitais, escolas. O Brasil não economiza em nada tipo a copa do ano passado deixaram de construir hospitais (estudante 41, gênero feminino, 14 anos, $9^{\circ}$ ano).

Não está nas melhores condições. Exemplo: a falta de água no Brasil. Essa falta de água foi boa em certo ponto pois ensinam as pessoas a economizar, porém nem todas as pessoas entendem a situação e desperdiçam (estudante 87, gênero feminino, 13 anos, $9^{\circ}$ ano).

Conforme as narrativas elencadas, depreendemos que parte dos estudantes tende a refletir sobre as consequências da crise no sentido de buscar soluções que minimizem os impactos dessa situação desgastante. Por um lado, percebemos uma tendência em valorizar as ideias de melhoria política e social cuja finalidade seria o combate ao desemprego, o fomento à moradia e acesso a alimentação. Por outro lado, valoriza-se a necessidade de melhoria econômica, ação atribuída não apenas ao governo, que deve priorizar os investimentos, mas também ao cidadão, que deve adquirir uma consciência financeira para evitar o desperdício.

\section{Discussões}

De maneira geral, os dados revelaram uma consciência prévia acerca de temas do Brasil hodierno, posto que, ao responder o enunciado do instrumento, não solicitamos que os estudantes fizessem algum tipo de consulta. Pela maneira como formulamos a questão, percebemos que os participantes se limitaram a apresentar fatos imediatos, cujas causas não eram buscadas em acontecimentos passados. Portanto, as explicações giraram em torno de concepções sobre "crise" que, talvez tenha se aproximado de temas trabalhados em sala de aula, a exemplo da "crise de 1929" - muito embora não tenha sido mencionado -, mas em geral, faziam parte de seu conhecimento imediato.

Segundo Lee (2005), os conceitos que nos ajudam a compreender o mundo não são precisamente definidos, por isso, não podemos exigir o mesmo dos jovens em sala de aula. Dessa forma, observamos que "os conceitos sociais dos estudantes emergiram de um modo de vida atual e adequaram-se a padrões de comportamento que podem não ser completamente entendidos, mas são tão 'normais' que, para os estudantes eles representam o que as coisas são" (LEE, 2005, p. 63-4, tradução nossa). As ideias apresentadas são, portanto, 
resultantes de uma experiência delicada da história recente do Brasil, cujos problemas começam a instigar diferentes pesquisadores interessados em identificar as conjunturas de uma história política baseada em confrontos nos quais diferentes grupos sociais se enfrentam (MACHADO; TOLEDO, 2017).

$\mathrm{Na}$ tentativa de apresentar mais elementos acerca do conceito substantivo citado com mais frequência (crise), os jovens procuraram argumentar por meio de explicações. Conforme Chapman (2008), esse tipo de operação mental se desenvolve mediante o uso de ferramentas conceituais como "causa" e "consequência". Submetido às dimensões intencionais e contextuais, o pensamento causal deve favorecer a compreensão dos desejos, saberes e pensamentos dos agentes históricos, bem como o contexto em que surgem essas intenções (CHAPMAN, 2008).

Para Lee e Shemilt (2009), a história deveria contribuir para que os estudantes percebessem "como" e "por que" as ações do passado chegam ao presente, entendendo, por exemplo, como as consequências de decisões individuais e ações coletivas podem nos conduzir a um futuro mais ou menos desejável. Ainda que seja limitada, a explicação é uma das operações do pensamento histórico capaz de favorecer a construção do presente, articulado a um passado e direcionado a um futuro - construído, sobretudo, a partir de "condições iniciais" localizadas nesse passado-presente. Embora não queiramos categorizá-las em níveis de progressão, podemos percebê-las a partir de algumas características extraídas da tipologia construída por Lee e Shemilt (2009).

Assim, observamos que, de maneira geral, as ideias aventadas pelos participantes demonstraram o domínio da linguagem causal, evidenciada em expressões como "por causa" e "porque", não obstante a ausência dos aparatos relacionados à explicação histórica, como a analogia e o pensamento contrafactual, por exemplo. Por outro lado, as respostas também implicaram na compreensão de agentes (como Dilma Rouseff e Michel Temer), entidades (como partidos políticos) e os mais diferentes fatores (corrupção, política e economia) que causaram o evento mencionado (a crise). Contudo, representadas por uma minoria, as ações e intenções desses agentes se constituíram como os elementos essenciais das explicações, como se estes fossem os únicos fatores a contribuir com a situação esboçada.

Caso analisássemos as ideias dos participantes em termos de progressão, estas respostas poderiam ser categorizadas entre os dois primeiros níveis, de uma escala composta por cinco, e, talvez não representassem "explicações válidas", tal como afirmam Lee e Shemilt (2009). Para isso, seria necessário que os jovens esboçassem ao menos um encadeamento causal, conseguindo atribuir significados para o curso da história (nível 3); ou percebessem as causas como 
elementos localizados em um contexto específico, aventando diferentes possibilidades em relação ao passado para que as expectativas de futuro pudessem ser flexibilizadas (nível 4); ou finalmente, que percebessem a influência de situações contingenciais em diferentes contextos (nível 5) (LEE; SHEMILT, 2009).

Embora o desenvolvimento do pensamento histórico seja desejável e, mesmo, esperado, não consideramos as respostas dos participantes inválidas. Certamente, os pesquisadores ingleses concordariam conosco quando afirmamos que tais explicações foram "melhores do que nada" (LEE; SHEMILT, 2009), na medida em que nos permitiu identificar parte das concepções espontâneas do grupo pesquisado. Desse modo, torna-se possível refletir sobre estratégias que favoreçam ao desenvolvimento do pensamento histórico deste ou de outros grupos semelhantes.

Considerando as operações mentais relacionadas à explicação causal, o trabalho docente deve ser pautado na diferenciação e categorização desse tipo de pensamento para que se possa destacar os fatores de importância de um determinado acontecimento. Nesse sentido, as explicações causais podem ser analisadas a partir de duas perspectivas: a primeira que entende as possibilidades causais; $\mathrm{e}$ a segunda que entende as determinações causais (CHAPMAN, 2008). De modo geral, as explicações apresentadas pelos participantes desse estudo eram muito incisivas ao pontuar, por exemplo, a "corrupção" como causa determinante da "crise". Portanto, não houve uma preocupação em levantar diferentes hipóteses, ou quando mencionadas, não apresentavam relações entre si.

Para Chapman (2008), diferentes estratégias podem ser utilizadas no sentido de auxiliar os estudantes na elaboração de explicações causais mais específicas como, por exemplo, o desenvolvimento de tarefas que explorem o pensamento contrafactual, isto é, tarefas capazes de incitar os jovens a pensar sobre o que poderia ter acontecido se um ou outro fator não tivesse ocorrido. Além desse estímulo, pode-se contribuir com o desenvolvimento do vocabulário do estudante, de maneira que ele reconheça outras expressões semelhantes à "causa", como "motivo", "razão", dentre outras (WOODCOCK, 2005; CHAPMAN, 2008, 2015; EVANS; PATE, 2007). Nesse sentido, é possível que o docente se aproprie de técnicas de progressão (scaffolding techniques), por meio das quais, poderão contribuir com o desenvolvimento do pensamento causal de seus estudantes (EVANS; PATE, 2007).

À guisa de conclusão, é notório destacar que, mesmo não tendo explorado as operações do pensamento mais complexas, como a evidência ou a interpretação, percebemos que os/as jovens conseguem atribuir sentidos aos conteúdos históricos com base em seus conhecimentos prévios. Entretanto, eles precisam ir além. Assim, vale ressaltar, uma vez mais, a importância de professoras e professores como mediadores/as das operações mentais que se concretizam 
nas aulas de História. Para tanto, é preciso combatermos movimentos que nos últimos anos têm ganhado força, ameaçando não apenas a liberdade de ensino destes profissionais, mas sobretudo sua integridade física. Além disso, precisamos estar atentos aos revisionismos que, ressurgindo das profundezas da ignorância, ameaçam as Ciências Humanas, ameaçam a Educação brasileira, ameaçam o futuro dos nossos jovens.

\section{REFERÊNCIAS}

ALVES, Ronaldo C. Aprender história com sentido para a vida: consciência histórica em estudantes brasileiros e portugueses. Tese (Doutorado em Educação) - Universidade de São Paulo, São Paulo, 2011.

BARCA, Isabel. Literacia e consciência histórica. Educar, Curitiba, Especial, p. 93-112, 2006.

BARCA, Isabel. O pensamento histórico dos jovens: ideias dos adolescentes acerca da provisoriedade da explicação histórica. Braga: Universidade do Minho, 2000.

BOGDAN, Robert C.; BIKLEN, Sari K. Investigação qualitativa em educação: uma introdução à teoria e aos métodos. Porto: Porto Editora, 1994.

CAINELLI, Marlene. Didática da história e a competência de atribuição de sentido: um estudo a partir da metodologia da educação histórica. Educar em Revista, Curitiba, Brasil, v. 35, n. 74, p. 55-67, mar./abr. 2019. Disponível em: https://revistas.ufpr.br/ educar/article/view/64400/38451. Acesso em: 09 jul. 2019.

CAMARGO, Brígido V.; JUSTO, Ana Maria. IRAMUTEQ: um Software Gratuito para Análise de Dados Textuais. Temas em Psicologia, v. 1, n. 2, p. 513-518, 2013. Disponível em: http://pepsic.bvsalud.org/pdf/tp/v21n2/v21n2a16.pdf. Acesso em: 20 jul. 2016.

CHAPMAN, Arthur. Cause and consequence. In: A Guide to the Key Stage 3 programme. Historical Association, 2008. Disponível em: https://www.history.org.uk/secondary/ categories/488/module/1215/a-guide-to-the-key-stage-3-programme/1268/24-causeand-consequence. Acesso em: 20 abr. 2018.

CHAPMAN, Arthur. Developing historical and metahistorical thinking in history classrooms: reflections on research and practice in England. Diálogos, Maringá, v. 19, n. 1, p. 29-55, jan./abr. 2015. Disponível em: http://periodicos.uem.br/ojs/index.php/ Dialogos/article/view/33802. Acesso em: 19 mar. 2016.

EVANS, Jennifer; PATE, Gemma. Does scaffolding make them fall? Reflecting on strategies for developing causal argument in Years 8 and 11. Teaching History, The Historical Association, 128, p. 18-29, set. 2007. Disponível em: https://www.history. org.uk/secondary/resource/736. Acesso em: 24 abr. 2018. 
REIS, A. S. C. Pensamento histórico de jovens estudantes sobre o Brasil...

HOUAISS, Antônio. Dicionário Eletrônico Houaiss da Língua Portuguesa. Rio de Janeiro: Objetiva, 2009. 1 CD-ROM, versão 3.0.

KITSON, Alison; HUSBANDS, Chris; STEWARD, Susan. Didáctica de la Historia en Secundaria Obligatoria y Bachillerato. Trad. Pablo Manzano Bernárdez. Madrid: Ediciones Morata, 2015.

LEE, Peter. Em direção a um conceito de literacia histórica. Educar, Curitiba, p. 131-150, 2006. Número especial. Disponível em: https://revistas.ufpr.br/educar/article/view/5543. Acesso em: 25 fev. 2014.

LEE, Peter. History education and historical literacy. In: DAVIES, Ian (ed.). Debates in history teaching. London: Routledge, 2011, p. 63-72.

LEE, Peter. Literacia histórica e história transformativa. Educar em Revista, Curitiba, n. 60, p. 107-146, abr./jun. 2016. Disponível em: http://www.scielo.br/pdf/er/n60/19840411-er-60-00107.pdf. Acesso em: 12 maio 2018.

LEE, Peter. Putting principles into practice: understanding History. In: DONOVAN, M. Suzanne; BRANDSFORD, John D. (editors). How students learn: history, mathematics and science in the classroom. Washington, D.C.: The National Academies Press, 2005, p. 31-78.

LEE, Peter; SHEMILT, Denis. Is any explanation better than none? Over-determined narratives, senseless agencies and one-way streets in students' learning about cause and consequence in history. Teaching History, The Historical Association, 137, p. 42-49, dec. 2009. Disponível em: https://www.history.org.uk/secondary/resource/2995/is-anyexplanation-better-than-none. Acesso em: 21 abr. 2018.

MACHADO, André Roberto de A.; TOLEDO, Maria Rita de A. (orgs.). Golpes na história e na escola: o Brasil e a América Latina nos séculos XX e XXI. São Paulo: Cortez, ANPUH SP, 2017.

RIBEIRO, Regina Maria de O. "Tudo isso antes do século XXI"-Estruturas e significados em narrativas da História do Brasil por estudantes do Ensino Fundamental. Tese (Doutorado em Educação) - Universidade de São Paulo, São Paulo, 2012.

RÜSEN, Jörn. Razão Histórica. Teoria da história: os fundamentos da ciência histórica. Tradução Estevão de Rezende Martins. Brasília: Editora da Universidade de Brasília, 2001.

RÜSEN, Jörn. Teoria da história: uma teoria da história como ciência. Tradução Estevão C. de Rezende Martins. Curitiba: Editora UFPR, 2015.

SCHMIDT, Maria Auxiliadora. Jovens brasileiros, consciência histórica e vida prática. Revista História Hoje, v. 5, n. 9, p. 31-48, 2016. Disponível em: https://rhhj.anpuh.org/ RHHJ/article/view/232. Acesso em: 12 mar. 2017.

SCHMIDT, Maria Auxiliadora. Perspectivas da consciência histórica e da aprendizagem em narrativas de jovens brasileiros. Tempos históricos, v. 12, p. 81-96, jan./jun. 2008. Disponível em: http://saber.unioeste.br/index.php/temposhistoricos/article/viewFile/ 1945/1537. Acesso em: 15 out. 2016. 
SCHMIDT, Maria Auxiliadora; GARCIA, Tânia Maria F. B. A formação da consciência histórica de alunos e professores e o cotidiano em aulas de história. Cad. Cedes, Campinas, vol. 25, n. 67, p. 297-308, set./dez. 2005. Disponível em: http://www.scielo.br/pdf/ccedes/ v25n67/a03v2567.pdf. Acesso em: 15 out. 2016.

SEFFNER, Fernando. Três territórios a compreender, um bem precioso a defender: estratégias escolares e Ensino de História em tempos turbulentos. In: MONTEIRO, Ana Maria; RALEJO, Adriana (orgs.). Cartografias da Pesquisa em Ensino de História. Rio de Janeiro: Mauad X, 2019, p. 21-42.

SIMÃO, Ana Catarina. Repensando a evidência histórica na construção do conhecimento histórico. In: PRATS, Joaquín; BARCA, Isabel; FACAL, Ramón (orgs.). Atas do V Simposio Internacional de Didáctica de las Ciencias Sociales en el ámbito Iberoamericano \& Congresso Internacional das XIII Jornadas de Educação Histórica. Braga: Universidade do Minho, p. 1247-1259, 2013.

STRAUSS, Anselm; CORBIN, Juliet. Pesquisa Qualitativa: técnicas e procedimentos para o desenvolvimento de teoria fundamentada. $2^{\mathrm{a}}$ ed. Porto Alegre: Artmed, 2008.

WINEBURG, Sam. Unnatural and essential: the nature of historical thinking. Teaching History, The Historical Association, 129, p. 6-11, dec. 2007. Disponível em: https://www. history.org.uk/secondary/resource/2429/unnatural-and-essential-the-nature-of-historical. Acesso em: 13 abr. 2018.

WOODCOCK, James. Does the linguistic release the conceptual? Helping Year 10 to improve their causal reasoning. Teaching History, The Historical Association, 119, p. 5-14, 2005. Disponível em: https://www.history.org.uk/secondary/resource/112/doesthe-linguistic-release-the-conceptual-helpin. Acesso em: 23 abr. 2018.

Texto recebido em 10/07/2019.

Texto aprovado em 27/04/2020. 